\title{
Diskriminasi imigran kulit putih berwarna dalam masa kebijakan multikulturalisme pasca penghapusan White AustraliaPolicy
}

\author{
Sandy Tieas Rahmana Poetrie \\ Magister Kajian Sastra dan Budaya, Fakultas Ilmu Budaya \\ Universitas Airlangga Surabaya, Jawa Timur, Indonesia. \\ E-mail: sandyputri98@yahoo.com
}

\begin{abstract}
This paper concern on the multiculturalism in Australia related to the immigration policy. Since the application of "White Australia Policy" which makes some restriction to people from other countries who are considered as different color and non-English speakers to come to Australia ended in 1907, the government attempts to eliminate the discrimination treatments to them all. This paper employs descriptive essay which was aimed to describe more about Australian multiculturalism after the end of "White Australia Policy". The technique of data collection was literary study from some sources like journals and some news from internet. The writer took three cases have ever happened related to the multiculturalism in Australia to analyse the application of immigrants policy after "White Australia Policy" annulment. Those are Arabians beating in Sydney coast by Neo-Nazi, discrimination against Muslim minority and Africans by police in Victoria, and also Muslim demonstration because of Muhammad humiliation. The study revealed that "White Australia Policy" still can not completely be eliminated. Those three cases, it shows that there are still many discrimination treatments against coloured immigrants; on the other hand the government is still trying to implement a multiculturalism policy.
\end{abstract}

Keywords: discrimination, multiculturalism, immigrants, White Australia policy.

\section{Pendahuluan}

Menengok sejarah perkembangan Australia, pada tahun 1901 pemerintahan Australia memberlakukan kebijakan yang berkenaan dengan imigan yang masuk ke wilayah Australia. Kebijakan ini disebut "Immigration Restriction Act" atau yang dikenal dengan sebutan "White Australia Policy". Dapat dilihat penggunaan istilah "restriction" yang dalam bahasa Indonesia dapat diartikan sebagai sebuah pembatasan. Pembatasan dalam hal ini adalah pembatasan terhadap imigran yang masuk ke Australia, terutama untuk orang-orang kulit berwarna. Kebijakan ini didasari oleh pemikiran untuk membentuk suatu negara dimana penduduknya adalah orang-orang dengan ras kulit putih saja. Masyarakat ras kulit putih dianggap superior dibandingkan dengan ras kulit berwarna.

Namun pada tahun 1907 kebijakan White Australia Policy ini dipertimbangkan kembali dengan alasan penguatan dalam bidang pertahanan dan ekonomi pemerintahan Australia. Sebagai negara "benua imigran", pemerintah Australia sulit untuk terus-menerus menerapkan kebijakan White Australia Policy. Australia pada waktu itu sedang membutuh banyak pekerja untuk mendorong 
pertumbuhan ekonomi mereka. Kebijakan pertahanan juga ingin agar ada kebijakan yang bersifat lebih plural atau sekuler. Para imigran diharapkan mampu membantu terwujudnya kekuatan pemerintah Australia dalam bidang pertahanan dan ekonomi. Secara resmi semangat multikulturalisme diimplementasikan dalam kebijakan negara Australia setelah adanya penghapusan White Australia Policy tersebut. Berbagai kebijakan yang cocok dengan situasi Australia yang kini beragam dan plural pun diterbitkan oleh pemerintah negara itu.

Secara umum diketahui Kebanyakan warga Negara Australia adalah orang pendatang dan bukan Suku Aborigin. keragaman ini disebabkan oleh banyaknya pendatang yang datang dari berbagai belahan di dunia, yang bermukim, bekerja, belajar, atau mencari suaka di Australia Barat. Oleh karena itu perbedaan bahasa, ras, budaya, agama dan kepercayaan bukanlah hal yang asing di negara ini. Arus imigrasi inilah yang sangat memberikan andil terhadap pertumbuhan penduduk Australia. Meskipun orang Australia mempunyai asal-usul yang berbeda baik dalam hal etnis, agama dan ras, mereka diharapkan hidup damai antara yang satu dengan yang lainnya. Terdapat kebijakan toleransi terhadap kebudayaan dan bangsa yang berlainan yakni adanya kebijakan Australia yang melindungi orang dari adanya diskriminasi. Kebijakan untuk bersikap toleran dan untuk melindungi kebudayaan dan kepercayaan yang berbeda tersebut disebut kebijakan multikulturalisme. Kebijakan multikulturalisme di Australia ini dimaksudkan untuk menjaga kerukunan antar sesama dengan tetap mempertahankan kebudayaan atau agama masing-masing.

Penghapusan kebijakan White Australia Policy yang digantikan dengan kebijakan multikulturalisme nyatanya terlihat tidak sepenuhnya menghapus adanya deskriminasi atau pembedaan terhadap warga kulit berwarna. Masih terjadi pasang surut hubungan antara warga kulit putih dan warga kulit berwarna pasca penghapusan kebijakan White Australia Policy. Oleh karena itu, penulis tertarik untuk mengetahui lebih jauh mengenai aplikasi kebijakan multikulturalisme pasca penghapusan White Australia Policy oleh pemerintahan Australia. Adapun rumusan masalah yang diambil penulis dalam makalah ini yaitu bagaimana kebijakan multikulturalisme terhadap penduduk kulit berwarna di Australia pasca penghapusan White Australia Policy?

\section{Metode}

Dalam penulisan makalah ini, penulis menggunakan teknik studi pustaka dengancar mencari sumber-sumber yang relevan dengan topik makalah yang penulis pilih, bisa berupa buku, artikel-artikel dalam internet, serta jurnal internasional. Dalam analisis temuan dalam makalah ini, penulis mengkaitkan kejadian atau kasus-kasus yang terjadi di Australia dengan teori multikulturalisme yang relevan dan kemudian dianalisis sehingga terlihat hasil yang ingin diketahui. 


\section{Kerangka teori}

\section{Pemberlakuan White Australia Policy}

Telah dijelaskan secara singkat dalam latar belakang bahwa White Australia Policy adalah sebuah kebijakan pemerintah dalam menyikapi besarnya imigran yang masuk ke wilayah Australia. Kebijakan ini dilakukan dengan cara memberlakukan pembatasan terhadap imigran yang masuk ke Australia, terutama untuk imigran-imigran kulit berwarna. Pada awalnya kebijakan ini ditujukan kepada imigran-imigran dari negara Cina yang jumlahnya yang sangat besar. Akhirnya seiring perkembangan waktu akhirnya kebijakan ini berlaku untuk seluruh warga rasa kulit berwarna. Hal ini disebabkan adanya ideologi bahwa masyarakat ras kulit putih dianggap superior dibandingkan dengan ras kulit berwarna, bahkan mereka tidak mengakui keberadaan ras Aborigin sebagai penduduk asli Australia. Pemerintah Australia yang mayoritas berasal dari Inggris ingin membentuk sebuah negara yang penduduknya utuh dari ras kulit putih. Hal ini menunjukkan adanya rasa ketakutan terhadap bangsa Asia yang jumlahnya terus-menerus meningkat sehingga terdapat kemungkinan besar di masa mendatang penduduk kulit putih akan menjadi minoritas.

Kebijakan White Australia Policy ini mempunyai sebuah instrumen yang dinamakan "Dictation test" yang harus dilalui oleh para imigran. Tes ini merupakan sebuah tes tulis dan wawancara untuk mengetes para imigran atas kemampuan mereka menggunakan bahasa di salah satu negara Eropa (Jupp. 1991: 48). Hal ini jelas terlihat bahwa yang dikehendaki oleh pemerintah Australia untuk masuk dalam wilayah mereka yakni orang-orang yang berasal dari Eropa, dan secara otomatis mengeliminasi orang-orang non-Eropa. Kebijakan ini mempunyai beberapa maksud, pertama Hal ini dimaksudkan agar keturunan Eropa bisa tetap berkembang di wilayah Australia tanpa dirusak adanya pertumbuhan ras non-Eropa. Kedua, imigran kulit berwarna akan menyebabkan kurangnya lapangan pekerjaan bagi masyarakat golongan buruh kulit putih. White Australia Policy akhirnya menjadi sebuah ideologi yang rasis.

Kebijakan White Australia Policy diberlakukan pada masa yang dikenal sebagai demam emas atau "gold rush" dimana ditemukan banyak emas di bumi Australia pada tahun 1851. Emas yang melimpah ruah ini mengundang banyak imigran baik dari Eropa ataupun non-Eropa seperti Asia untuk berpindah ke tanah Australia. Persebaran berita mengenai demam emas ini membuat jumlah pendatang meningkat. Pada dasarnya imigran mulai berdatangan pada abad ke 19 ketika para pemerintahan Australia menyewa para imigran Asia untuk dipekerjakan (labour movement) di perkebunan dan peternakan (London, 1970: 7). Hal ini meningkatkan jumlah imigran Asia terutama Cina secara besar-besaran. Dan menurut Barnard Marjorie (1976) dalam bukunya "History of Australia" bahwa "Immigrant Act" pada tahun 1855 merupakan awal dari kemunculan peraturan yang bersifat rasis.

Namun, pada tahun 1973 kebijakan White Australia Policy diberhentikan. Karena sebagai negara benua imigran, pemerintah Australia tidah 
bisa memberlakukan kebijakan ini lagi. Semakin banyak imigran masuk dan mereka tidak hanya berasal dari ras kulit putih, sehingga kebijakan White Australia Policy tidak lagi dianggap sesuai untuk Australia.

\section{Negara Multikulturalisme menurut Kymlicka}

Multikulturalisme yang merujuk pada sebuah spirit, etos, dan kepercayaan bahwa kelompok-kelompok etnik atau budaya (ethnic and cultural group) dapat berdampingan secara damai yang ditandai dengan kesediaan untuk menghormati budaya lain (KID, 2004), mengusung kebutuhan tiap-tiap masyarakat tertentu akan pengakuan identitas mereka. Faktanya, kita semakin sering dihadapkan pada kelompok-kelompok minoritas yang menuntut pengakuan atas identitas mereka serta diterimanya perbedaan budaya mereka (Kymlicka, 2011: 13).

Konsep multikulturalisme memiliki karakteristik celebrating diversity dan negosiasi terhadap perbedaan. Suatu kelompok masyarakat memerlukan pengakuan atas identitas mereka. Hal ini yang janjikan oleh multikulturalisme dimana setiap individu atau kelompok bisa mengekspresikan siapa mereka dalam masyarakat plural. Jika multikulturalisme berjalan sesuai dengan tujuannya, masyarakat akan bersikap toleran, beradaptasi, memberikan kesempatan serta menghargai satu sama lain yang berbeda identitas. Kymlicka (2011) mengemukakan terdapat dua aspek munculnya multikulturalisme, yakni migrasi yang masuk ke suatu daerah dan adanya kebanggaan sebagai minoritas
Kymlicka dalam bukunya "Kewargaan Multikultural" lebih menitikberatkan definisi multikulturalisme sebagai akibat dari munculnya 'minoritas bangsa' dan juga 'kelompok etnis'. Ia menyebut negara sebagai Negara multikulturalisme ketika sekelompok bangsa-bangsa tertentu masuk dari suatu negara yang lebih besar, atau ketika sekelompok masyarakat telah melakukan imigrasi dan masuk ke suatu negara (2011: 13-14). Dapat disimpulkan bahwa yang disebut sebagai negara multikulturalisme itu apabila anggotanya berasal dari berbagai bangsa (negara multibangsa) atau telah beremigrasi dari berbagai bangsa (negara polietnis). Multikulturalisme dalam konteks ini lebih fokus untuk mengakomodasi perbedaan-perbedaan etnis dan bangsa sebagai perjuangan besar untuk membuat demokrasi yang lebih toleran dan inklusif (2011: 26).

\section{Multikulturalisme di Australia}

Masyarakat yang plural tidak otomatis menjadi multikulturalisme. Multikulturalisme menekankan keanekaragaman kebudayaan dalam kesederajatan. Tidak ada satu budaya pun yang mendominasi dalam masyarakat plural tersebut. Dengan demikian, dominasi maupun peleburan diasumsikan tidak terjadi dalam konteks multikulturalisme. Visualisasinya adalah seperti salad bowl di mana berbagai unsur menyatu tanpa kehilangan identitasnya bukan melting pot yang menghilangkan latar belakang dan menghasilkan identitas baru hasil peleburan (Rira, 2012).

Istilah multikulturalisme mulai muncul di Australia pada tahun 1973 yang disampaikan oleh 
Al Grassby selaku menteri keimigrasian pemerintahan, yang didefinisikan oleh Wollacott sebagai " a policy that encourage migrant groups to embrace their ethnic culture, provide that they abide by Australian Laws" (2012:295). Sama halnya dengan apa yang dikemukakan oleh Kymlicka, Grassy menyebut multikulturalisme sebagai suatu masyarakat yang menikmati kebebasan dalam menunjukkan perbedaan-perbedaan kewarganegaraan dan etnis (Wollacott, 2012: 295).

Multikulturalisme di Australia pada tahun 1997 meliputi empat aspek kebijakan yakni social cohesion, cultural identity, equality of opportunity and equal responsibility dan participate in Australian society (Wollacott, 2012: 297). Namun, berdasarkan hasil penelitian yang dilansir oleh pemerintah Australia mengenai anggapan masyarakat Australia mengenai konsep multikulturalisme yang berjudul "Multiculturalism for Australians", hasil menunjukkan bahwa masih banyak masyarakat yang belum mengetahui konsep secara jelas mengenai multikuturalisme yang diterapkan di negara mereka.

\section{Pembahasan dananalisis}

Di bagian pembahasan dan analisis dalam makalah ini, penulis akan menyajikan beberapa contoh kejadian-kejadian atau kasus yang berkaitan dengan penerapan konsep multikulturalisme oleh pemerintah Australia pasca penghapusan kebijakan White Australia Policy. Dalam pembahasan ini nantinya akan terlihat apakah kebijakan multikulturalisme yang diterapkan pemerintahan
Australia sudah berjalan dengan baik atau bahkan pengaruh kebijakan White Australia Policy masih terasa dalam setiap kebijakan yang dikeluarkan pemerintah Australia.

Wicaksono (2006) melihat masih adanya perlakuan diskriminatif warga kulit putih, yang sebenarnya juga merupakan pendatang, terhadap orang-orang Aborigin dan komunitas-komunitas Muslim atau Arab di Australia. Hal ini terjadi dikarenakan selain bermotif ekonomi juga menunjukkan motif politik dan kekuasaan. Peristiwa tragis pada tanggal 11 Desember 2005 menjadi salah satu contoh dimana ribuan masyarakat Australia berkulit putih melakukan penyerangan terhadap orang-orang yang dianggap keturunan Arab di pantai Sidney. Kerusuhan yang pecah pada hari Minggu di wilayah selatan Sydney, seperti Cronulla Beach, Maroubra Beach, dan Botany Bay di pinggiran kota terbesar di negara berpenduduk lebih dari 20 juta jiwa itu mengakibatkan 31 orang cidera (Media Indonesia Online, 2005). Kelompok-kelompok yang terlibat dalam penyerangan tersebut adalah kelompokkelompok Neo-Nazi dan kelompok pengagung kulit putih (penganut White Australia Policy).

Pada kenyataannya walaupun disangkal oleh beberapa pihak dari pemerintaha Australia, kerusuhan di Pantai Sidney memang melibatkan unsur rasisme didalamnya dan mungkin juga unsur agama (anti-Muslim). Wicaksono (2006) melihat bahwa Pemerintah Australia sebenarnya menyetujui adanya rasisme melalui kebijakan-kebijakannya yang tegas terhadap imigran, pengungsi, dan keamanan nasional. Juga pemberlakuan undang-undang anti- 
terorisme yang menimbulkan ketidakpercayaan warga Autralia kulit puttih terhadap orang-orang keturunan Arab dan Muslim di Australia. Hal ini bisa jadi salah satu penyebab terjadinya kerusuan Pantai Sidney.

Menurut Saakshi O. Juneja, seorang feminis yang berdomisili di India, memastikan bahwa keanekaragaman budaya dan ras di Australia berpengaruh besar terhadap tumbuhnya benih rasialisme (dalam Wicaksono, 2006). Mayoritas penduduk pendatang merupakan orang berkulit putih yang secara kompak menentang kebijakan imigrasi, Hal ini menegaskan bahwa penyakit rasialisme masih saja menggejala walaupun kebijakan White Australia Policy sudah dihapus. Konsep multikulturalisme di Australia mungkin bisa berjalan di tingkatan pemerintahan, namun dalam tingkatan masyarakat umum belum bisa dikatakan berjalan dengan baik. Hal ini dimungkinkan adanya ketidakfahaman terhadap konsep multikulturalisme, seperti apa yang telah disampaikan oleh pemerintah Australia dalam penelitian mereka "Multiculturalism for Australians"

Pemerintah Australia tidak serta merta mendukung kebijakan yang melarang adanya imigrasi. Pemerintah Australia berusaha menetapkan konsep multikulturalisme di Australia dengan benar. Salah satu contohnya adalah kejadian kerusuhan pada saat unjuk rasa warga Muslim yang menuntut penghinaan terhadap Nabi Muhammad SAW. Pemerintah Australia sangat kecewa dengan adanya kerusuhan yang anarkis tersebut. Tanpa melihat ras dan agama para pengunjuk rasa, pemerintah Australia memutuskan untuk segera mendeportasi pelaku-pelaku yang terbukti melakukan keanarkisan. Mereka menganggap bahwa para pengunjuk rasa justru mencoreng dan merusak kebijakan multikulturalisme yang telah diterapkan di Australia. Menurut Chris Bowen selaku Menteri keimigrasian menganggap peristiwa ini dianggap bukan merupakan sebuah upaya multiklturalisme, namun atas nama anarkisme dan kejahatan (ABC Radio Online: 2012). Hal ini didukung oleh statemen yang dilontarkan oleh Perdana Menteri Australia Julia Gillard "Apa yang kita lihat di jalanan kota Sydney pekan lalu, bukanlah multikulturalisme, melainkan ekstremisme". Ia juga menambahkan bahwa segala perdebatan dan perbedaan harusnya dapat diselesaikan dengan damai (Adiputri, 2012).

Merujuk pada apa yang telah dikemukakan oleh Kymlica (2011), multikulturalisme memiliki karakteristik celebrating diversity dan negosiasi terhadap perbedaan. Dikaitkan dengan apa yang terjadi di Australia, konsep ini belum bisa dijalankan dengan baik. Peristiwa-peristiwa kerusuhan yang berbau rasisme masih banyak ditemui. Padahal, dalam konteks pemikiran Kymlicka definisi multikulturalisme lebih fokus untuk mengakomodasi perbedaan-perbedaan etnis dan bangsa sebagai perjuangan besar untuk membuat demokrasi yang lebih toleran dan inklusif. Kasus pengeroyokan warga dari etnis Arab menjadi satu bukti bahwa masyarakat Australia kulit puth belum mampu mengakomodasi perbedaan dan bersikap toleran kepada imigran-imigran lain yang berasal dari etnis dan agama yang berbeda. 
Kasus rasial secara spesifik dirasakan oleh kaum minoritas Muslim dan Afrika yang berada di Australia. Pelakunya kali ini bukan masyarakat Australia kulit putih pada umumnya seperti pelaku pengeroyokan orang keturunan Arab pada tahun 2005, namun pelakunya yakni aparat polisi yang merupakan bagian dari pemerintah Australia. Kejadian ini baru saja terjadi pada Agustus 2012 lalu, ketika aparat kepolisian bagian Victoria sering merazia komunitas muslim dan imigran asal Afrika. Stiap melewati jalur tertentu di wilayah Victoria, aparat polisi selalu melakukan pemeriksaan dengan cara mencecar komunitas Muslim and orang asal Afrika dengan banyak pertanyaan seolah-olah mereka berpotensi melakukan tindak pidana. Seorang pengacara Melbourne bernama Tamar Hopskin mengemukakan jika terbukti aparat kepolisian telah melakukan kebijakan deskriminasi (rasial), itu artinya mereka telah melanggar UndangUndang Federasi mengenai deskriminasi ras (Mardani, 2012).

Contoh-contoh kasus diatas menunjukkan bahwa pemberlakuan kebijakan multikulturalisme di Australia belum cukup bisa berjalan dengan baik. Namun pada dasarnya pemerintah telah mengalakkan kebijakan multikulturalisme ini untuk dapat diterapkan di seluruh wilayah Australia yang memang mayoritas penduduknya adalah pendatang. Dari beberapa contoh diatas mungkin dapat ditarik suatu kesimpulan bahwa baik pemerintah Australia sendiri atau masyarakat Australia secara menyeluruh terutama penduduk berkulit putih kurang bisa memahami dan menerima konsep multikulturalisme secara penuh. Semua pihak harusnya dapat memahami konsep multikulturalisme dengan menghargai dan saling bertoleransi dengan adanya perbedaan yang ada disekeliling mereka. Empat aspek multikulturalisme yang digagas oleh pemerintah Australia yang meliputi social cohesion, cultural identity, equality of opportunity and equal responsibility dan participate in Australian society (Wollacott, 2012:

297) belum bisa terealisasi secara menyeluruh kepada seluruh imigran yang ada tanpa ada pembedaan atau deskriminasi. Seolah-olah pengaruh kebijakan White Australia Policy, yang menganggap kulit putih lebih superior daripada orang-orang kulit berwarna, masih melekat kuat sebagai sebuah ideologi yang terus-menerus berkembang dalam pemikiran penduduk Australia kulit putih.

\section{Simpulan}

Penghapusan White Australia Policy atau pembatasan imigran yang digantikan dengan kebijakan multikulturalisme di Australia diharapkan mampu mengahapuskan segala deskriminasi dan menumbuhkan sikap toleran serta membina kerukunan antar imigran yang berasal dari negaranegara yang berbeda. Namun, dalam perkembangannya, kebijakan multikulturalisme belum bisa diterapkan secara menyeluruh dalam masyarakat. Terdapat beberapa kejadian atau kasus yang menggambarakan tetap eksisnya deskriminasi baik warna kulit, ras, etnis ataupun agama, seperti tragedi pengeroyokan orang keturunan Arab di Pantai Sidney pada 11 September 2005, kerusuhan 
unjuk rasa para Muslim karena adanya penghinaan terhadap Nabi Muhammad, serta deskriminasi rasial secara terang-terangan oleh aparat kepolisian bagian Victoria terhadap kaum minoritas Muslim dan imigran keturunan Afrika. Kurang faham dan kurang terimanya masyarakat terhadap konsep multikulturalisme turut andil dalam kurang tercapainya tujuan pemerintah menerapkan kebijakan tersebut. Pengaruh White Australia Policy masih terbawa sampai saat ini sehingga secara keseluruhan penduduk Australia kulit putih belum melihat orang-orang kulit berwarna secara setara sehingga belum bisa untuk saling menghormati dan toleransi.

\section{Daftar Acuan}

ABC Radio Online. 2012. Pengunjuk rasa yang bukan warga negara Australia terancam dideportasi.

http://www.radioaustralia.net.au/indonesian/2 012-09-18/pengunjuk-rasa-yang-bukan-warganegara-australia-terancamdideportasi/1016948. Diakses pada 16 Januari 2013.

Adiputri, Novi C. 2012. PM Australia Sebut Aksi Demo 'Innocence of Muslims' Ekstremisme. DetikNews Edisi 20 Spetember 2012. http://news.detik.com/read/2012/09/20/140647/20 27716/1148/pm-australia-sebut-aksi-demoinnocence-of-muslimsekstremisme?nd771108bcj. Diakses pada 16 Januari 2013.
Jupp, James. 1991. Immigration. Sidney: Sidney University Press and Oxford University Press Australia.

KID, Pustaka. 2004. Multikulturalisme Indonesia: Jawaban terhadap Kemajemukan. http://www.komunitasdemokrasi.or.id/comme nts.php?id=P18_0_3_0_C. Diakses pada 17 Januari 2013.

Kymlicka, Will. 2011. Kewargaan Multikutural. Jakarta: LP3ES

London, H.I. 1970. Non-White Immigration and the 'White Australis' Policy. Sidney: Sidney University Press.

Mardani, Dewi. 2012. Komunitas Muslim Jadi Korban Rasial Polisi Australia. Republika Online Edisi 28 Agustus 2012. http://www.republika.co.id/berita/duniaislam/islam-mancanegara/12/08/27/m9etp8komunitas-muslim-jadi-korban-rasial-polisiaustralia

Media Online Indonesia. 2005. Terkait Kerusuhan Sydney, RI Belum Keluarkan 'Travel Warning". http://www.perspektif.net/article/article.php?ar ticle_id=222. Diakses pada 17 Januari 2013.

Rira. 2012. Multikulturalisme: Pengakuan atau Pengaburan Identitas Masyarakat? http://kkcygnet.wordpress.com/2012/06/29/m ultikulturalisme-pengakuan-atau-pengaburanidentitas-masyarakat/. Diakses pada 16 Januari 2013.

Soebantardjo. 1958. Sari Sedjarah Asia-Australia. Jogjakarta: Bopkri 
Wollacott et. al. 2012. History for the Australian Curriculum 10. London: Cambridge University Press.

Wicaksono, Dani. 2005. Rasialisme di Australia. http://daniwicaksono.blogspot.com/2006/11/r asialisme-di-australia.html. Diakses pada 16 Januari 2013. 